University of Wollongong

Research Online

Australian Institute for Innovative Materials -

Papers

Australian Institute for Innovative Materials

$1-1-2016$

\title{
pH-responsive Fe(III)-gallic acid nanoparticles for in vivo photoacoustic imaging-guided photothermal therapy
}

Jianfeng Zeng

Soochow University, China

Ming Cheng

Soochow University, China

Yong Wang

Soochow University, China

Ling Wen

Soochow University, China

Ling Chen

Soochow University, China

See next page for additional authors

Follow this and additional works at: https://ro.uow.edu.au/aiimpapers

Part of the Engineering Commons, and the Physical Sciences and Mathematics Commons

Research Online is the open access institutional repository for the University of Wollongong. For further information contact the UOW Library: research-pubs@uow.edu.au 


\title{
pH-responsive Fe(III)-gallic acid nanoparticles for in vivo photoacoustic imaging- guided photothermal therapy
}

\author{
Abstract \\ pH-responsive biocompatible Fe(III)-gallic acid nanoparticles with strong near-infrared absorbance are \\ very stable in mild acidic conditions, but easily decomposed in neutral conditions, which enables the \\ nanoparticles to be stable in a tumor and easily metabolized in other organs, thus providing a safe \\ nanoplatform for in vivo photoacoustic imaging/photothermal therapy theranostic applications. \\ Disciplines \\ Engineering | Physical Sciences and Mathematics

\section{Publication Details} \\ Zeng, J., Cheng, M., Wang, Y., Wen, L., Chen, L., Li, Z., Wu, Y., Gao, M. \& Chai, Z. (2016). pH-responsive \\ $\mathrm{Fe}$ (III)-gallic acid nanoparticles for in vivo photoacoustic imaging-guided photothermal therapy. Advanced \\ Healthcare Materials, 5 (7), 772-780.

\section{Authors} \\ Jianfeng Zeng, Ming Cheng, Yong Wang, Ling Wen, Ling Chen, Zhen Li, Yongyou Wu, Mingyuan Gao, and \\ Zhifang Chai
}


DOI: $10.1002 /(($ please add manuscript number $))$

Article type: Communication

\section{pH-Responsive Fe(III)-Gallic-Acid Nanoparticles for In-Vivo Photoacoustic Imaging Guided Photothermal Therapy}

Jianfeng Zeng, Ming Cheng, Yong Wang, Ling Wen, Ling Chen, Zhen Li, * Yongyou Wu, * Mingyuan Gao, * Zhifang Chai

Dr. J. F. Zeng, L. Wen, Dr. Y. Wang, Prof. Z. Li, L. Chen, Prof. Z. F. Chai

Center for Molecular Imaging and Nuclear Medicine, School for Radiological and

Interdisciplinary Sciences (RAD-X), Soochow University

Collaborative Innovation Center of Radiation Medicine of Jiangsu Higher Education

Institutions

Suzhou 215123, China

Email: zhenli@suda.edu.cn

M. Cheng, Prof. Y. Y. Wu

The Second Affiliated Hospital of Soochow University

Suzhou 215004, China

Email:wuyoyo@aliyun.com

Prof. Z. Li

Institute for Superconducting \& Electronic Materials

The University of Wollongong

NSW 2500, Australia

Prof. M. Y. Gao

Institute of Chemistry, Chinese Academy of Sciences

Beijing National Laboratory for Molecular Sciences (BNLMS)

Beijing 100190, China

Email: gaomy@iccas.ac.cn

Keywords: pH-sensitive nanoparticles; metal complex nanoparticles; photoacoustic imaging; photothermal therapy 
Nanomaterials integrated with different therapeutic and diagnostic functional agents have attracted considerable attention in recent years due to their great potential in precision medicine. ${ }^{[1]}$ To date, large quantities of theranostic agents for simultaneous use in different imaging and therapeutic technologies, such as magnetic resonance imaging - photothermal therapy (MRI-PTT), ${ }^{[2]}$ optical imaging - photodynamic therapy (PDT), ${ }^{[3]}$ MRIchemotherapy, ${ }^{[4]}$ computed tomography $(\mathrm{CT})-\mathrm{PTT},{ }^{[5]}$ and photoacoustic imaging (PAI)-PTT, ${ }^{[6]}$ were fabricated from individual functional agents, which could be detached from each other during circulation and metabolism in vivo, leading to different biodistributions and pharmacokinetics, inaccurate diagnosis, and poor therapy efficacy. Therefore, it is important to develop theranostic platforms based on single material which can serve as both imaging agent and therapeutic agent. ${ }^{[7]}$

Near-infrared (NIR) absorbing materials have strong absorption in the region of 700-3000 nm. An advantage of this type of material is their capability of converting the NIR light, which can penetrate into deep tissues, into heat for photoacoustic imaging (PAI) and thermal ablation of malignant tumors. ${ }^{[5-6,8]}$ PAI shows distinct advantages over the traditional optical imaging, including low signal scattering in tissues, and high resolution and sensitivity. Photothermal therapy (PTT) is a promising noninvasive alternative to traditional cancer therapies, which has attracted considerable interest in recent years due to its highly specific selectivity towards the targeted sites. The combination of PTT and PAI could provide a perfect solution for accurate diagnosis and treatment of cancer, because they could both use the same NIR absorbing material as theranostic agent without any need to consider detachment of different functional units after intravenous administration.

The currently available NIR-absorbing materials include NIR dyes, ${ }^{[9]}$ gold nanomaterials, ${ }^{[10]}$ carbon nanomaterials, ${ }^{[6,11]}$ upconversion nanoparticles, ${ }^{[12]}$ transition-metal dichalcogenides, ${ }^{[13]}$ and some organic polymers. ${ }^{[14]}$ In comparison with small molecular NIR dyes, NIR absorbing nanomaterials with proper surface modification exhibit longer blood 
circulation time for tumor targeting. In addition, due to the enhanced permeability and retention (EPR) effect, nanomaterials also have longer retention time in tumor sites than small molecules, and provide a much longer time window for tumor diagnosis and therapy. Nevertheless, most exogenous nanomaterials are easily taken up by the reticuloendothelial system (RES), e.g., liver and spleen, which could cause potential risks of toxicity due to long retention time if they are difficult to degrade and metabolize in vivo. Therefore, the development of nanotheranostic agents that are subject to fast metabolism in normal organs and tissues, but have long retention time in tumors is of great importance for their practical applications.

Herein, we report a novel PAI-PTT theranostic agent based on $\mathrm{pH}$-sensitive Fe(III)-gallicacid nanoparticles with strong NIR absorbance, which can be easily decomposed under neutral conditions, but remain stable under acidic conditions. Due to the weak acidic condition in tumors, which is different from that in normal tissue, our Fe(III)-gallic-acid nanoparticles could be retained in tumor sites, while being easily decomposed and metabolized in other organs, leading to excellent in-vivo photoacoustic imaging and a good photothermal therapy effect against tumors in mice.

It is well known that transition metal ions generally have incompletely filled $d$ orbitals. When ligands bond to them to form complexes, the electrons in the ligands and the electrons in the $d$ orbitals of metal ions interact with each other and induce splitting of the $d$ orbitals, resulting in $d$ - $d$ electronic transitions and subsequent absorption of light under excitation. As the $d$ - $d$ transitions of metal ions strongly depend on the ligand properties, the absorbance of metal ion complexes can be adjusted in the ultraviolet-visible (UV-Vis) and even the NIR region by manipulating the ligands and their coordination chemistry. An example is Fe(III)gallic-acid complex with strong NIR absorbance prepared by simply mixing $\mathrm{FeCl}_{3}$ solution with gallic acid solution, which features a bluish-violet color, as shown in Figure 1a, due to the $d-d$ electronic transitions. The corresponding UV-Vis-NIR absorption spectra display wide 
absorption from 400 to $900 \mathrm{~nm}$, with a peak centered at $575 \mathrm{~nm}$.

The as-prepared complex solution exhibits strong $\mathrm{pH}$-dependent stability. It is very stable when the solution $\mathrm{pH}$ is above 5.0, and no precipitates or particles were detected after one week by dynamic light scattering (DLS) measurements. When the $\mathrm{pH}$ is lower than 5.0, the complex can gradually aggregate and form nanoparticles, as shown in Figure $1 \mathrm{~b}$ and Figure $\mathrm{S} 1$ in the Supporting Information. The hydrodynamic size reaches up to $\sim 45 \mathrm{~nm}$ within $72 \mathrm{~h}$ at $\mathrm{pH}$ 4.5. Decreasing the solution $\mathrm{pH}$ from 4.5 to 3.7 leads to fast aggregation and formation of nanoparticles, and their hydrodynamic size reaches $\sim 45 \mathrm{~nm}$ within $2 \mathrm{~h}$. The strong $\mathrm{pH}-$ dependent stability is closely related to the protonation/deprotonation of carboxyl groups ($\mathrm{COOH}$ ) in gallic acid. As the acid dissociation constant $(\mathrm{pKa})$ of $-\mathrm{COOH}$ in gallic acid is around 4.5 , the electrostatic repulsion induced by deprotonation of $-\mathrm{COOH}$ can effectively prevent the aggregation of the $\mathrm{Fe}(\mathrm{III})$-gallic-acid complex. When the $\mathrm{pH}$ is lower than or equal to the pKa, however, the electrostatic repulsion decreases significantly, and the hydrophobic interactions among the complex molecules lead to the formation of Fe(III)gallic-acid nanoparticles. It is worth noting that the aggregation and formation of Fe(III)gallic-acid nanoparticles is reversible. Figure 1c shows the evolution of the hydrodynamic size of $\mathrm{Fe}(\mathrm{III})$-gallic-acid nanoparticles incubated in aqueous media with different $\mathrm{pH}$. There is no obvious change in the hydrodynamic size of the Fe(III)-gallic-acid nanoparticles when the solution $\mathrm{pH}$ is changed from 3.7 to 5.0 , indicating the high stability of the thus-formed Fe(III)-gallic-acid nanoparticles under acidic conditions. Further increasing the solution $\mathrm{pH}$ leads to a gradual decrease in the hydrodynamic size due to the disassembling of Fe(III)gallic-acid nanoparticles into small complex molecules again.

The above results indicate that Fe(III)-gallic-acid nanoparticles can directly be obtained by mixing $\mathrm{FeCl}_{3}$ solution with gallic acid, and the size of the nanoparticles can be easily controlled by adjusting the solution $\mathrm{pH}$ and the reaction time. More importantly, the resultant nanoparticles can be directly used without any further purification. This environmentally 
friendly method provides a simple way to prepare $\mathrm{pH}$-responsive inorganic/organic nanoparticles for biomedical applications. The resultant Fe(III)-gallic-acid nanoparticles are stable at $\mathrm{pH}$ of 5.0 , but unstable under neutral conditions $(\mathrm{pH}=7)$. Their $\mathrm{pH}$-dependent stability suggests that they could be stable in tumors because of the weak acidic microenvironment in tumors, and unstable in other normal tissues, which indicates that they may have a long retention time at tumor sites, but be quickly metabolized in other organs.

In the following study, we used Fe(III)-gallic-acid nanoparticles prepared by mixing $\mathrm{FeCl}_{3}$ with gallic acid under $\mathrm{pH} 3.7$ for $2 \mathrm{~h}$ to investigate their potential as a PAI-PTT theranostic agent. The transmission electron microscope (TEM) image shows that they have an average size of $42.6 \mathrm{~nm}$ (Figure 1d and 1e), which is consistent with their hydrodynamic size of $45 \mathrm{~nm}$ (Figure 1f). Due to the strong NIR absorption, the Fe(III)-gallic-acid nanoparticles show obvious photoacoustic and photothermal effects. As shown in Figure 1g, the photoacoustic signal increases with increasing iron concentration from $0.05 \mathrm{mM}$ to 1.0 $\mathrm{mM}$, indicating that the Fe(III)-gallic-acid nanoparticles would be good candidates for PAI. To evaluate their photothermal performance, Fe(III)-gallic-acid nanoparticles with various concentrations from $0.1 \mathrm{mM}$ to $1.5 \mathrm{mM}$ were exposed to an 808 -nm NIR laser with a power density of $0.5 \mathrm{~W} / \mathrm{cm}^{2}$. The temperature of each solution was recorded for $10 \mathrm{~min}$ under continuous laser irradiation until the solution reached a steady temperature. As shown in Figure $1 \mathrm{~h}$ and Figure S2, the temperature difference $(\Delta T)$ drastically increases with the increasing particle concentration. The temperature of the Fe(III)-gallic-acid nanoparticle solution with a concentration of $1.5 \mathrm{mM}$ can increase by $53{ }^{\circ} \mathrm{C}$ after irradiation for $10 \mathrm{~min}$. The temperature of pure water was only increased by $2{ }^{\circ} \mathrm{C}$ under the same conditions. In addition, their photothermal performance remains rather stable after five cycles of NIR laser irradiation (808-nm laser at $0.5 \mathrm{~W} / \mathrm{cm}^{2}, 10 \mathrm{~min}$ for each cycle) as shown in Figure 1 i. Furthermore, the photothermal conversion efficiency of Fe(III)-gallic-acid nanoparticles was 
calculated to be $66.8 \%$ (Figure S3), which is relatively high compared with those reported for NIR dyes, ${ }^{[16]}$ gold nanomaterials, ${ }^{[7 \mathrm{~b},}{ }^{15]}$ carbon nanomaterials, ${ }^{[17]}$ transition-metal dichalcogenides, ${ }^{[2 c, 8 d, 18]}$ and polymer nanoparticles. ${ }^{[14 a, 19]}$ These results suggest that Fe(III)gallic-acid nanoparticles would be an effective photothermal agent for cancer therapy, as cancer cells can be killed by being kept at $50{ }^{\circ} \mathrm{C}$ for several minutes.

Considering the excellent photothermal performance of Fe(III)-gallic-acid nanoparticles for potential cancer treatment, we further investigated their in-vitro cytotoxicity and PTT efficacy. The cytotoxicity was evaluated through methyl thiazolyl tetrazolium (MTT) assays on the proliferation of 4T1 cells (murine breast cancer cells). As shown in Figure 2a, the cell viability remained above $80 \%$ after incubation with $100 \mu \mathrm{M}$ nanoparticles for $24 \mathrm{~h}$, and $50 \%$ of the cells survived at $200 \mu \mathrm{M}$. To verify their photothermal ablation of cancer cells, 4T1 cells were incubated with Fe(III)-gallic-acid nanoparticles at various concentrations for $24 \mathrm{~h}$ and then exposed to an irradiation $(808 \mathrm{~nm})$ with a power density of $0.5 \mathrm{~W} / \mathrm{cm}^{2}$ for $10 \mathrm{~min}$. After the irradiation, an MTT assay was performed to quantitatively determine the cell viability (Figure 2b). The results clearly show that the cell viability decreased drastically with increasing nanoparticle concentration, in comparison with the control groups without NIR laser irradiation (Figure 2a). With a concentration of $100 \mu \mathrm{M}$, more than $80 \%$ of the cells were dead after laser irradiation, suggesting the excellent anticancer performance of these nanoparticles, which was further demonstrated by staining the cells with a Live-Dead Cell Staining Kit after laser irradiation to differentiate the live and dead cells. Most cells were destroyed after incubation with $100 \mu \mathrm{M}$ Fe(III)-gallic-acid nanoparticles and exposure to irradiation with a 808-nm laser (Figure 2c). In contrast, only few cells died if they were not incubated with Fe(III)-gallic-acid nanoparticles and/or not exposed to laser irradiation. These results demonstrate that Fe(III)-gallic-acid nanoparticles could serve as a potential PTT agent for photothermal ablation of cancer cells. 
As mentioned previously, PTT agents could also serve as contrast agents for photoacoustic imaging. To further demonstrate the potential of $\mathrm{Fe}(\mathrm{III})$-gallic-acid nanoparticles in tumor imaging, a subcutaneously transplanted 4T1 tumor model was adopted. $\mathrm{BALB} / \mathrm{c}$ nude mice with different tumor sizes of 5-10 mm were selected to evaluate the photoacoustic (PA) imaging performance of Fe(III)-gallic-acid nanoparticles (4 mM, $200 \mu \mathrm{L}$ for each mouse), which were intravenously injected through the tail vein. A set of PA images of the tumor region acquired before and at different time points post-injection are presented in Figure 3a. The overall contrast of the tumor area was gradually enhanced after injection of $\mathrm{Fe}(\mathrm{III})$-gallic-acid nanoparticles, indicating a continuing accumulation of nanoparticles in the tumor area via blood circulation. The accumulation of nanoparticles at the tumor site could be attributed to the enhanced permeability and retention (EPR) effect, which is a common mechanism for passive targeting of nanoparticles. It is reasonable to expect the accumulation of our nanoparticles at the tumor site because their size is suitable for the EPR effect. In addition, the signal enhancement is more pronounced for large tumors, demonstrating that nanoparticles could be more effectively taken up by large tumors than smaller ones. This is expected, because large tumors may have more tumor blood vessels that would give rise to a stronger EPR effect than in the smaller tumors. These results demonstrate that Fe(III)-gallicacid nanoparticles are an excellent photoacoustic imaging agent, which can significantly illuminate the tumor and clearly delineate the margin of the tumor.

To further quantitatively evaluate the performance of the Fe(III)-gallic-acid nanoparticles, the PA signals of the region of interest (ROI) in each image were calculated and are presented in Figure 3b. The quantified results reveal that, for all different sized tumors, Fe(III)-gallicacid nanoparticles produce increased contrast at the tumor site in the first $4 \mathrm{~h}$ post-injection, so that the contrast reaches its maximum value at around $8 \mathrm{~h}$, and then slightly decreases with the circulation time. The signal enhancement is more pronounced in large tumors than smaller ones, which is consistent with the images shown in Figure 3a. Furthermore, the results also 
suggest that the optimal time for irradiation would be $8 \mathrm{~h}$ after injection of Fe(III)-gallic-acid nanoparticles, at which the maximum accumulation of nanoparticles at the tumor site and their best PTT efficacy could be obtained. The effects of PA enhancement on different sized tumors are further demonstrated by comparison of the tumor signal obtained pre-injection with the maximum value obtained after injection (Figure 3c). Compared with the PA signal of the tumor site itself, the accumulation of $\mathrm{Fe}(\mathrm{III})$-gallic-acid nanoparticles could increase the signal by $61 \%, 235 \%$, and $403 \%$, respectively, for different sized tumors. Figure $3 \mathrm{c}$ also shows that a large tumor has a stronger PA signal than the smaller ones. As the PA signal of the tumor site obtained pre-injection is positively related to the blood content of tumor tissue, the above result suggests that a large tumor would have richer tumor blood vessels, which leads to a stronger EPR effect for the uptake of Fe(III)-gallic-acid nanoparticles.

Encouraged by the promising in-vitro photothermal ablation effect on cancer cells and the in-vivo PAI imaging of tumors, we further evaluated the photothermal effect of Fe(III)-gallicacid nanoparticles in vivo. According to the above in-vivo PAI results, mice bearing 4T1 tumors with different sizes were anesthetized after intravenous (IV) injection of Fe(III)-gallicacid nanoparticles ( $4 \mathrm{mM}, 200 \mu \mathrm{L}$ for each mouse) for $8 \mathrm{~h}$, which is the optimal time for accumulation of nanoparticles in a tumor, and then exposed to 808-nm irradiation with a power density of $1.0 \mathrm{~W} / \mathrm{cm}^{2}$. An infrared imaging camera was used to monitor the temperature changes in the tumor site under NIR irradiation. The temperature of the tumor area increased by $9.9,19.8$, and $24.4{ }^{\circ} \mathrm{C}$ within 10 min under laser irradiation for mice with tumor sizes of 60, 150, and $260 \mathrm{~mm}^{3}$ (Figure 3d and Figure 3e), respectively. In comparison, the tumor temperature of mice from the control group (i.e. intravenous injection of saline and then the same irradiation conditions) was only increased by $5.5^{\circ} \mathrm{C}$, much lower than for the mice injected with Fe(III)-gallic-acid nanoparticles. In addition, large tumors exhibited higher temperature than small ones. This should be attributed to more efficient uptake of Fe(III)gallic-acid nanoparticles by large tumors than smaller ones through the EPR effect. The 
consistency between the PTT and the PAI results suggests that the PA imaging can serve as an effective method to guide the photothermal ablation of tumors. The results also indicate the difficulty in photothermal ablation of small tumors due to less accumulation of nanoparticles in the tumor (i.e. less passive targeting of nanoparticles through the EPR effect). Nevertheless, for a tumor with a size of $150 \mathrm{~mm}^{3}$ in the current study, the increased temperature $(\Delta T=19.8$ ${ }^{\circ} \mathrm{C}$ ) would be high enough to ablate it in vivo. This size is comparable to those of tumors used for many PTT studies in the literature. ${ }^{[8 b, 20]}$

As photoacoustic imaging can also serve as a non-invasive imaging technique for semiquantifying the pharmacokinetics of drugs, we conducted a preliminary evaluation of the pharmacokinetics of Fe(III)-gallic-acid nanoparticles in mice by using the PAI method. Figure 4a displays the PA images of major organs of nude mice before and after injection of Fe(III)gallic-acid nanoparticles. The PA signals of each organ were calculated and are presented in Figure 4b-e. The signal change in the ischiatic vein was used to demonstrate the variation in the content of Fe(III)-gallic-acid nanoparticles in the blood. After injection of Fe(III)-gallicacid nanoparticles, the PA signal in the blood increased significantly and then gradually decreased, indicating the clearance of Fe(III)-gallic-acid nanoparticles from the blood. The PA signal of blood after $8 \mathrm{~h}$ is higher than that pre-injection, suggesting a long blood circulation time of $\mathrm{Fe}(\mathrm{III})$-gallic-acid nanoparticles. The retention time of $\mathrm{Fe}(\mathrm{III})$-gallic-acid nanoparticles in blood is much longer than the decomposition time of nanoparticles under the neutral condition, as shown in Figure 1c. This is due to the complicated environment and the protection provided by proteins in blood, which is evidenced by the slow degradation of Fe(III)-gallic-acid nanoparticles in $10 \%$ fetal bovine serum (FBS) in Figure S4. Although the decomposition of $\mathrm{Fe}$ (III)-gallic-acid nanoparticles in FBS is slower, they can be almost completely decomposed within one day, indicating the fast metabolic breakdown of Fe(III)gallic-acid nanoparticles. The PA signal of the kidney shows a similar trend to that in the blood, but the signal decreased much more slowly than the decay observed for blood, 
suggesting that renal excretion may be one of the metabolic pathways for Fe(III)-gallic-acid nanoparticles. The PA signals of the liver and spleen dramatically increased after $1 \mathrm{~h}$ postinjection, indicating the fast accumulation of $\mathrm{Fe}(\mathrm{III})$-gallic-acid nanoparticles in the liver and spleen. This is expected, as nanoparticles are easily captured by the reticuloendothelial system, leading to the strong PA signal. The PA signals of the liver and spleen reached an approximate plateau after $2 \mathrm{~h}$, and then gradually decreased from $4 \mathrm{~h}$ and $6 \mathrm{~h}$, respectively. After $24 \mathrm{~h}$, the PA signal of the liver and spleen recovered to the pre-injection level, indicating that the Fe(III)-gallic-acid nanoparticles in these organs may be gradually decomposed into small molecular complexes and then easily excreted from the treated animals. In remarkable contrast, the $\mathrm{Fe}(\mathrm{III})$-gallic-acid nanoparticles were still accumulating in the tumor after $24 \mathrm{~h}$ post-injection, as shown in Figure 3. The above results fully demonstrate that Fe(III)-gallicacid nanoparticles can be easily decomposed in the liver and spleen while remaining stable in the tumor with a long retention time. In addition, the clearance of $\mathrm{Fe}(\mathrm{III})$-gallic-acid nanoparticles in vivo takes place more quickly than for other nanomaterials studied in the literature ${ }^{[8 \mathrm{a}, 21]}$ demonstrating that $\mathrm{Fe}(\mathrm{III})$-gallic-acid nanoparticles could be a safe, promising candidate as a PAI-PTT theranostic agent.

To assess the in-vivo therapeutic potential of Fe(III)-gallic-acid nanoparticles, a further careful investigation of their photothermal therapeutic efficacy was carried out. Balb/c mice with subcutaneous $4 \mathrm{~T} 1$ tumors were selected as the animal model. After the tumor sizes reached approximately $150 \mathrm{~mm}^{3}$, the mice were divided into four groups with 5 mice per group. For the treatment group, they were intravenously injected with Fe(III)-gallic-acid nanoparticles ( $4 \mathrm{mM}, 200 \mu \mathrm{L}$ for each mouse). After $8 \mathrm{~h}$, their tumors were irradiated by an 808-nm laser for $10 \mathrm{~min}$ with a power density of $1 \mathrm{~W} / \mathrm{cm}^{2}$. The other three groups included the saline injection group, a group in which the mice were injected with saline and also exposed to the laser, and a group in which the mice were injected with Fe(III)-gallic-acid nanoparticles, but without laser irradiation. The tumor sizes were measured every day after 
treatment. For the treatment group, the tumor shrank remarkably after 1 day of photothermal treatment, and black scars were formed, which were completely eradicated 14 days after treatment (Figure 5a). In contrast, for the other three control groups, neither the laser irradiation with the current power density nor Fe(III)-gallic-acid nanoparticles alone could affect the tumor growth (Figure 5b). In addition, the mice in the control groups had an average lifespan of 30-33 days, shorter than for the treated mice, which were tumor-free after treatment and sacrificed on purpose after living for 45 days (Figure $5 \mathrm{c}$ ). The above results suggest that Fe(III)-gallic-acid nanoparticles could serve as a powerful PTT agent for in-vivo photothermal ablation of cancer.

To further demonstrate the in-vivo toxicity of Fe(III)-gallic-acid nanoparticles, the treated mice were sacrificed 45 days after treatment, and the major organs were collected, sliced, and stained by hematoxylin and eosin (H\&E) for histological analysis (Figure 5d). Compared with the normal mice, no noticeable inflammation or damage was observed in any of the major organs. The results indicate that Fe(III)-gallic-acid nanoparticles are not toxic to mice with the current experimental dosage. In addition, as the spread of cancer cells into the lung is the main metastasis of 4T1 tumors, Figure 5d also shows no appreciable signs of pulmonary metastasis for surviving mice with tumors that were photothermally ablated.

In summary, a new type of PAI-PTT nanotheranostic agent based on $\mathrm{pH}$-sensitive Fe(III)gallic-acid complex was successfully developed. The complex has a strong NIR absorbance and can reversibly aggregate into nanoparticles with a size that is controllable by simply changing the solution $\mathrm{pH}$ value. The resultant nanoparticles are stable under mild acidic conditions $(\mathrm{pH}$ around 5.0) and unstable under neutral $\mathrm{pH}$, which is perfectly suitable for cancer diagnosis and treatment, because the nanoparticles would be stable in the weak acidic environment of a tumor, while being easily metabolized in other organs. In-vitro experiments show that the Fe(III)-gallic-acid nanoparticles present low toxicity and excellent photothermal ablation of cancer cells, so that they can serve as an efficient photothermal agent. Further in- 
vivo PAI and PTT experiments showed that Fe(III)-gallic-acid nanoparticles are accumulated more in large tumors than in small ones because of the stronger EPR effect in the larger tumors. The results also suggest that PAI can be employed to guide the photothermal ablation of tumors. The pharmacokinetics results show that Fe(III)-gallic-acid nanoparticles have longer retention times in tumors than in the liver and spleen, where they can be easily degraded and excreted, due to their $\mathrm{pH}$-sensitivity. The in-vivo treatment results demonstrate that Fe(III)-gallic-acid nanoparticles are a highly effectively photothermal agent for NIR light-induced tumor ablation. In addition, no acute toxicity was observed for the Fe(III)gallic-acid nanoparticles in our experiments, demonstrating their excellent biocompatibility. Our research provides a new strategy for designing theranostic agents for cancer diagnosis and treatment through PAI/PTT.

\section{Supporting Information}

Supporting Information is available from the Wiley Online Library or from the author.

\section{Acknowledgements}

J. Zeng and M. Cheng contributed equally to this work. This work was partially supported by the National Natural Science Foundation of China (81471657, 81530057, and 21503141), Beijing National Laboratory for Molecular Sciences (20140165), China Postdoctoral Science Foundation (2015M570472). Z. Li acknowledges the support from the program of Jiangsu Specially Appointed Professorship. The authors also thank Dr. Tania Silver for polishing the manuscript.

Received: ((will be filled in by the editorial staff))

Revised: ((will be filled in by the editorial staff)) Published online: ((will be filled in by the editorial staff))

[1] a) Y. Chen, C. Tan, H. Zhang, L. Wang, Chem. Soc. Rev. 2015, 44, 2681; b) K. Yang, L. Z. Feng, X. Z. Shi, Z. Liu, Chem. Soc. Rev. 2013, 42, 530; c) E. Terreno, F. Uggeri, S. Aime, J. Control Release 2012, 161, 328.

[2] a) J. Li, Y. Hu, J. Yang, P. Wei, W. Sun, M. Shen, G. Zhang, X. Shi, Biomaterials 2015, 38, 10; b) X. Song, H. Gong, S. Yin, L. Cheng, C. Wang, Z. Li, Y. Li, X. Wang, G. Liu, Z. Liu, Adv. Funct. Mater. 2014, 24, 1194; c) Q. Tian, J. Hu, Y. Zhu, R. Zou, Z. Chen, S. Yang, R. Li, Q. Su, Y. Han, X. Liu, J. Am. Chem. Soc. 2013, 135, 8571.

[3] J. Lin, S. Wang, P. Huang, Z. Wang, S. Chen, G. Niu, W. Li, J. He, D. Cui, G. Lu, X. Chen, Z. Nie, ACS Nano 2013, 7,5320 .

[4] a) Y. Chen, D. L. Ye, M. Y. Wu, H. R. Chen, L. L. Zhang, J. L. Shi, L. Z. Wang, Adv. Mater. 2014, 26, 7019; b) E.-K. Lim, Y.-M. Huh, J. Yang, K. Lee, J.-S. Suh, S. Haam, Adv. Mater. 2011, 23, 2436.

[5] Z. Zhou, B. Kong, C. Yu, X. Shi, M. Wang, W. Liu, Y. Sun, Y. Zhang, H. Yang, S. Yang, Sci. Rep. 2014, 4, 3653.

[6] D. Chen, C. Wang, X. Nie, S. Li, R. Li, M. Guan, Z. Liu, C. Chen, C. Wang, C. Shu, L. Wan, Adv. Funct. Mater. 2014, 24, 6621. 
[7] a) J. C. Ge, Q. Y. Jia, W. M. Liu, L. Guo, Q. Y. Liu, M. H. Lan, H. Y. Zhang, X. M. Meng, P. F. Wang, Adv. Mater. 2015, 27, 4169; b) P. Huang, J. Lin, W. Li, P. Rong, Z. Wang, S. Wang, X. Wang, X. Sun, M. Aronova, G. Niu, R. D. Leapman, Z. Nie, X. Chen, Angew. Chem. Int. Edit. 2013, 52, 13958; c) J. C. Ge, M. H. Lan, B. J. Zhou, W. M. Liu, L. Guo, H. Wang, Q. Y. Jia, G. L. Niu, X. Huang, H. Y. Zhou, X. M. Meng, P. F. Wang, C. S. Lee, W. J. Zhang, X. D. Han, Nat. Commun. 2014, 5; d) P. Huang, P. F. Rong, J. Lin, W. W. Li, X. F. Yan, M. G. Zhang, L. M. Nie, G. Niu, J. Lu, W. Wang, X. Y. Chen, J. Am. Chem. Soc. 2014, 136, 8307.

[8] a) K. Yang, G. Yang, L. Chen, L. Cheng, L. Wang, C. Ge, Z. Liu, Biomaterials 2015, 38, 1; b) J. Yu, C. Yang, J. Li, Y. Ding, L. Zhang, M. Z. Yousaf, J. Lin, R. Pang, L. Wei, L. Xu, F. Sheng, C. Li, G. Li, L. Zhao, Y. Hou, Adv. Mater. 2014, 26, 4114; c) Q. Tian, Q. Wang, K. X. Yao, B. Teng, J. Zhang, S. Yang, Y. Han, Small 2014, 10, 1063; d) W. Yin, L. Yan, J. Yu, G. Tian, L. Zhou, X. Zheng, X. Zhang, Y. Yong, J. Li, Z. Gu, Y. Zhao, ACS Nano 2014, 8, 6922; e) D. Jaque, L. Martinez Maestro, B. del Rosal, P. Haro-Gonzalez, A. Benayas, J. L. Plaza, E. Martin Rodriguez, J. Garcia Sole, Nanoscale 2014, 6, 9494; f) L. M. Nie, X. Y. Chen, Chem. Soc. Rev. 2014, 43, 7132.

[9] A. Yuan, J. H. Wu, X. L. Tang, L. L. Zhao, F. Xu, Y. Q. Hu, J. Pharm. Sci. 2013, 102, 6.

[10] a) J. Shen, H.-C. Kim, C. Mu, E. Gentile, J. Mai, J. Wolfram, L.-n. Ji, M. Ferrari, Z.-w. Mao, H. Shen, Adv. Healthc. Mater. 2014, 3, 1629; b) J.-G. Piao, L. Wang, F. Gao, Y.-Z. You, Y. Xiong, L. Yang, ACS Nano 2014, 8, 10414. [11] a) Y. Wang, K. Wang, J. Zhao, X. Liu, J. Bu, X. Yan, R. Huang, J. Am. Chem. Soc. 2013, 135, 4799; b) X. Shi, H. Gong, Y. Li, C. Wang, L. Cheng, Z. Liu, Biomaterials 2013, 34, 4786.

[12] L. Cheng, K. Yang, Y. Li, J. Chen, C. Wang, M. Shao, S.-T. Lee, Z. Liu, Angew. Chem. Int. Edit. 2011, 50, 7385.

[13] L. Cheng, J. Liu, X. Gu, H. Gong, X. Shi, T. Liu, C. Wang, X. Wang, G. Liu, H. Xing, W. Bu, B. Sun, Z. Liu, Adv. Mater. 2014, 26, 1886.

[14] a) M. Chen, X. Fang, S. Tang, N. Zheng, Chem Commun 2012, 48, 8934; b) L. Cheng, K. Yang, Q. Chen, Z. Liu, ACS Nano 2012, 6, 5605.

[15] X. Ding, C. H. Liow, M. Zhang, R. Huang, C. Li, H. Shen, M. Liu, Y. Zou, N. Gao, Z. Zhang, Y. Li, Q. Wang, S. Li, J. Jiang, J. Am. Chem. Soc. 2014, 136, 15684.

[16] M. Zheng, P. Zhao, Z. Luo, P. Gong, C. Zheng, P. Zhang, C. Yue, D. Gao, Y. Ma, L. Cai, ACS Appl. Mater. Inter. 2014, 6, 6709.

[17] J. Q. Chen, X. P. Wang, T. S. Chen, Nanoscale Res. Lett. 2014, 9, 86.

[18] J. Liu, X. P. Zheng, L. Yan, L. J. Zhou, G. Tian, W. Y. Yin, L. M. Wang, Y. Liu, Z. B. Hu, Z. J. Gu, C. Y. Chen, Y. L. Zhao, ACS Nano 2015, 9, 696.

[19] J. Zhou, Z. Lu, X. Zhu, X. Wang, Y. Liao, Z. Ma, F. Li, Biomaterials 2013, 34, 9584.

[20] a) C. Yue, P. Liu, M. Zheng, P. Zhao, Y. Wang, Y. Ma, L. Cai, Biomaterials 2013, 34, 6853; b) H. Gong, Z. Dong, Y. Liu, S. Yin, L. Cheng, W. Xi, J. Xiang, K. Liu, Y. Li, Z. Liu, Adv. Funct. Mater. 2014, 24, 6492; c) M. Guo, H. Mao, Y. Li, A. Zhu, H. He, H. Yang, Y. Wang, X. Tian, C. Ge, Q. Peng, X. Wang, X. Yang, X. Chen, G. Liu, H. Chen, Biomaterials 2014, 35, 4656.

[21] a) L. Cheng, K. Yang, M. W. Shao, X. H. Lu, Z. Liu, Nanomedicine 2011, 6, 1327; b) W.-S. Cho, M. Cho, J. Jeong, M. Choi, B. S. Han, H.-S. Shin, J. Hong, B. H. Chung, J. Jeong, M.-H. Cho, Toxicol. Appl. Pharm. 2010, 245, 116; c) J. F. Zeng, B. Jia, R. R. Qiao, C. Wang, L. H. Jing, F. Wang, M. Y. Gao, Chem. Commun. 2014, 50, 2170; d) C. Y. Liu, Z. Y. Gao, J. F. Zeng, Y. Hou, F. Fang, Y. L. Li, R. R. Qiao, L. Shen, H. Lei, W. S. Yang, M. Y. Gao, ACS Nano 2013, 7, 7227. 

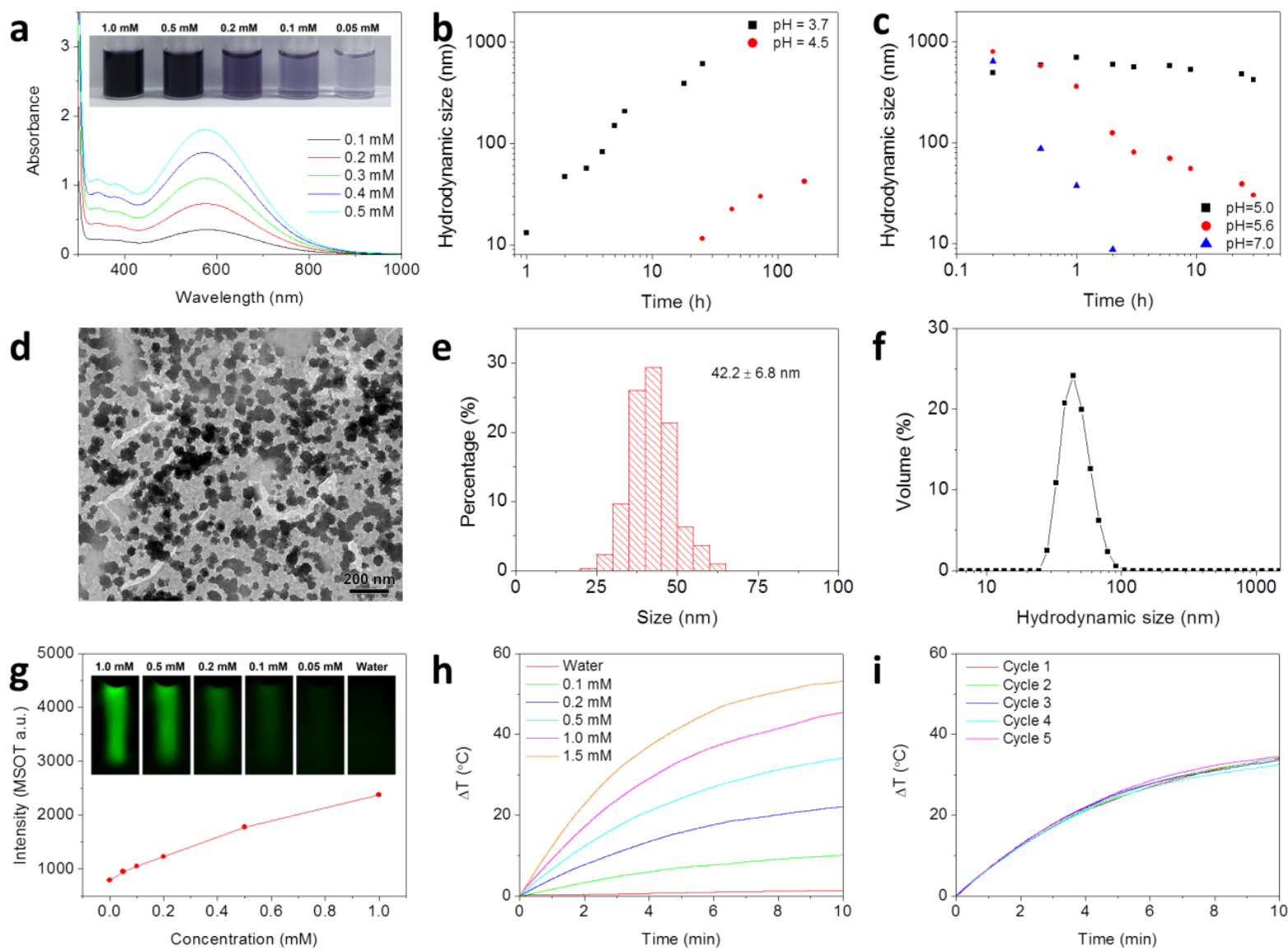

Figure 1. Synthesis and characterization of Fe(III)-gallic-acid nanoparticles. (a) UV-Vis-NIR absorbance spectra of Fe(III)-gallic-acid solution. Inset: Photographs of Fe(III)-gallic acid solutions with different iron concentrations. (b) Hydrodynamic size evolution of Fe(III)gallic-acid nanoparticles formed under different $\mathrm{pH}$. (c) Hydrodynamic size evolution of $\mathrm{Fe}$ (III)-gallic-acid nanoparticles incubated in aqueous media with different $\mathrm{pH}$. (d) TEM image of $\mathrm{Fe}$ (III)-gallic-acid nanoparticles prepared by mixing $\mathrm{FeCl}_{3}$ with gallic acid under $\mathrm{pH}$ 3.7 for $2 \mathrm{~h}$. (e) Corresponding TEM size distribution of Fe(III)-gallic-acid nanoparticles displayed in (d). (f) Hydrodynamic size distribution of Fe(III)-gallic-acid nanoparticles shown in (d). (g) Photoacoustic signals of Fe(III)-gallic-acid nanoparticles at $680 \mathrm{~nm}$ as a function of concentration. Inset: Photoacoustic images of different concentrations of Fe(III)-gallic-acid nanoparticles in agar phantom. (h) Temperature elevation of different concentrations of $\mathrm{Fe}$ (III)-gallic-acid nanoparticles as a function of irradiation time. (i) Temperature variation of $\mathrm{Fe}(\mathrm{III})$-gallic-acid nanoparticles $(0.5 \mathrm{mM})$ under irradiation for 5 cycles. 

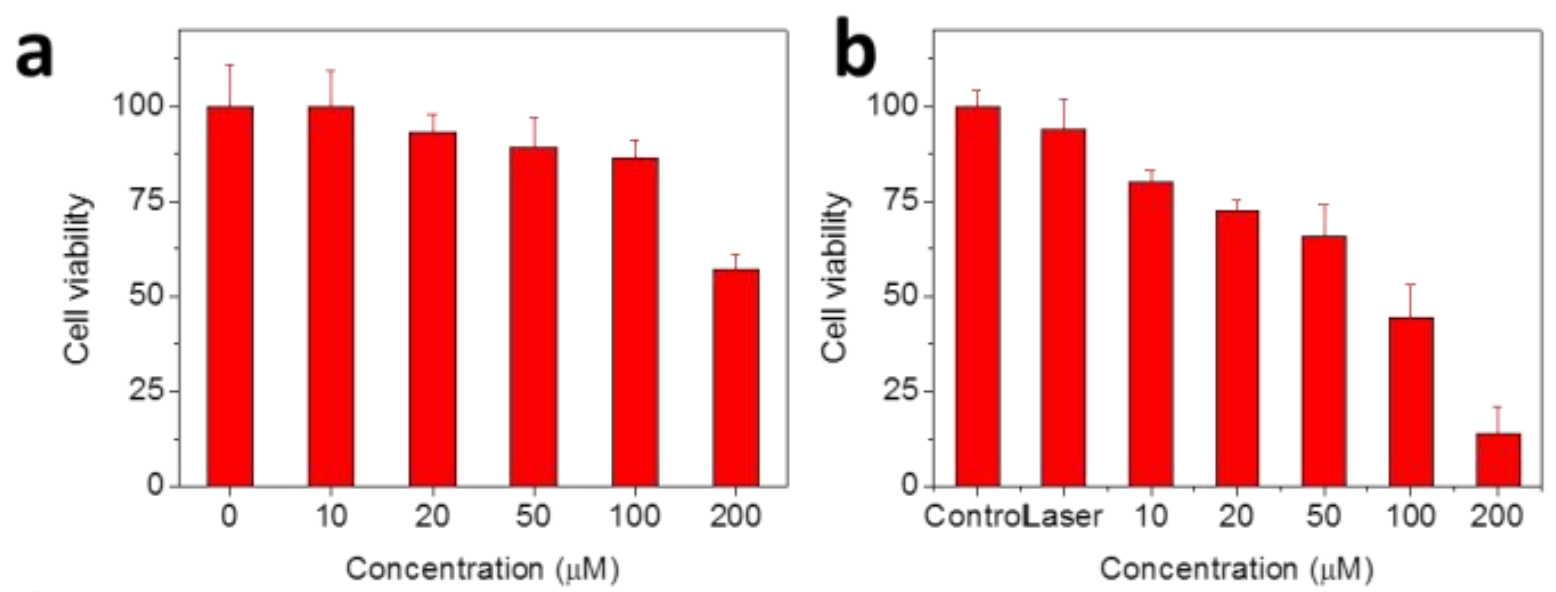

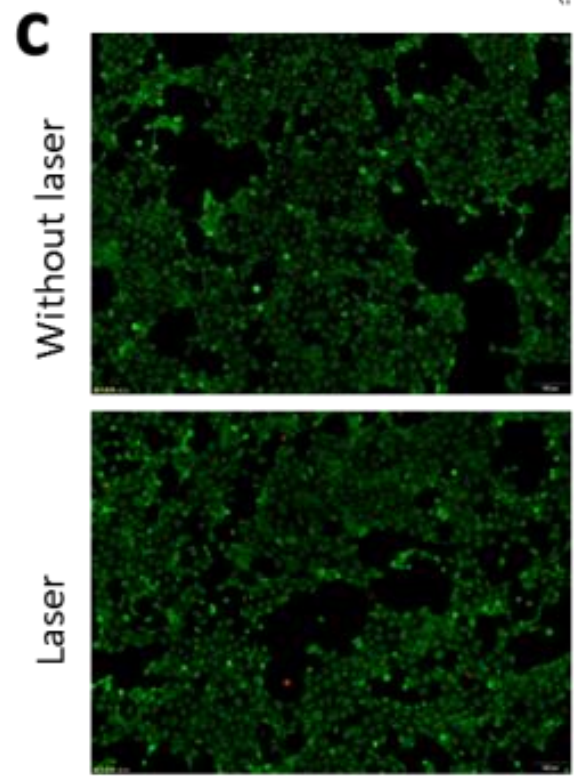

0
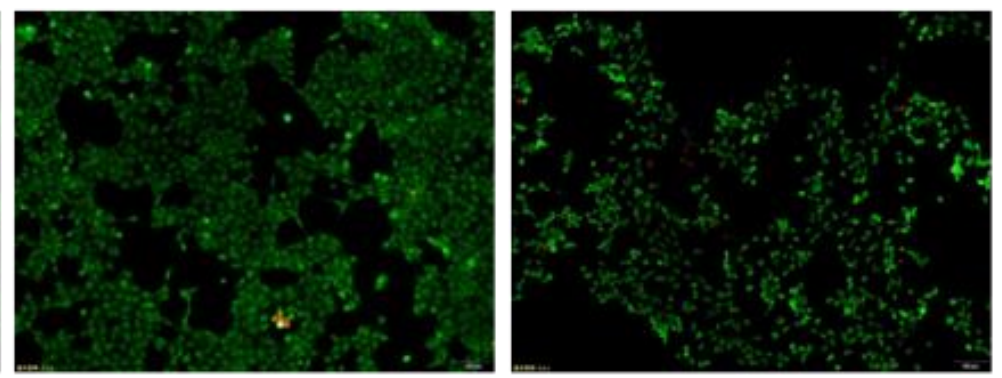

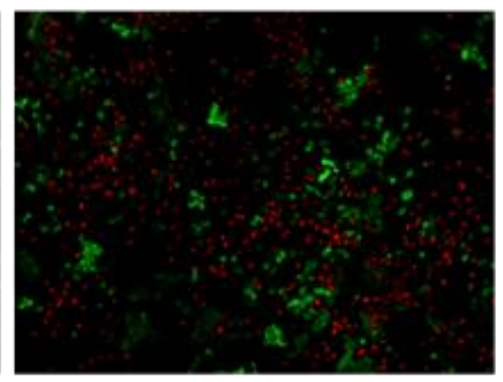

$100 \mu \mathrm{M}$

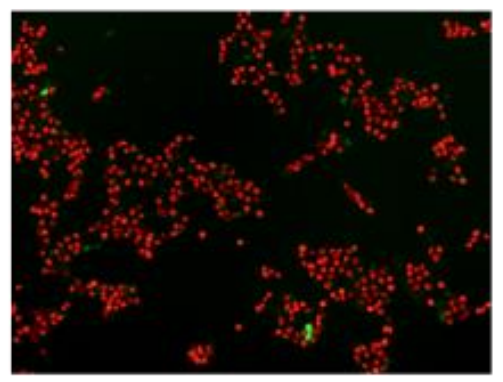

$200 \mu \mathrm{M}$

Figure 2. In-vitro cell experiments. (a) Relative cell viabilities of 4T1 cells after being incubated with various concentration of $\mathrm{Fe}$ (III)-gallic-acid nanoparticles for $24 \mathrm{~h}$. (b) Relative cell viabilities of 4T1 cells incubated with various concentration of $\mathrm{Fe}(\mathrm{III})$-gallic-acid nanoparticles under $808-\mathrm{nm}$ laser irradiation $\left(0.5 \mathrm{~W} / \mathrm{cm}^{2}, 10 \mathrm{~min}\right)$. (c) Live-Dead Cell Staining Kit stained images of 4T1 cells incubated with Fe(III)-gallic-acid nanoparticles at different concentrations after laser irradiation for $10 \mathrm{~min}$ at a power density of $0.5 \mathrm{~W} / \mathrm{cm}^{2}$. 
a
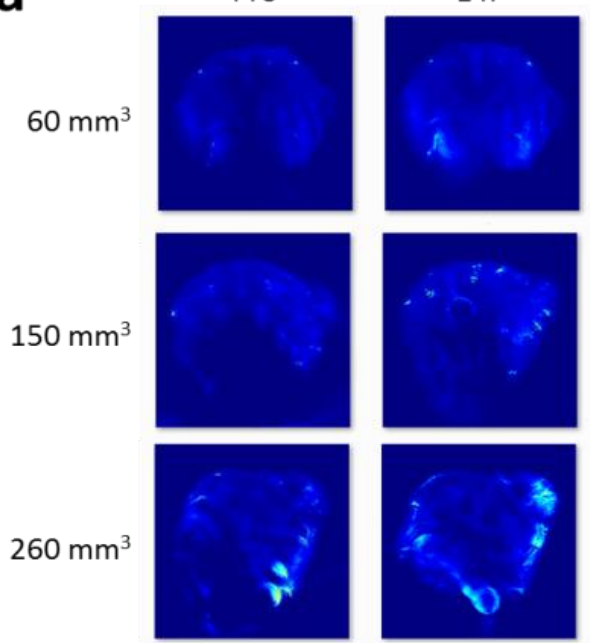

\section{b}
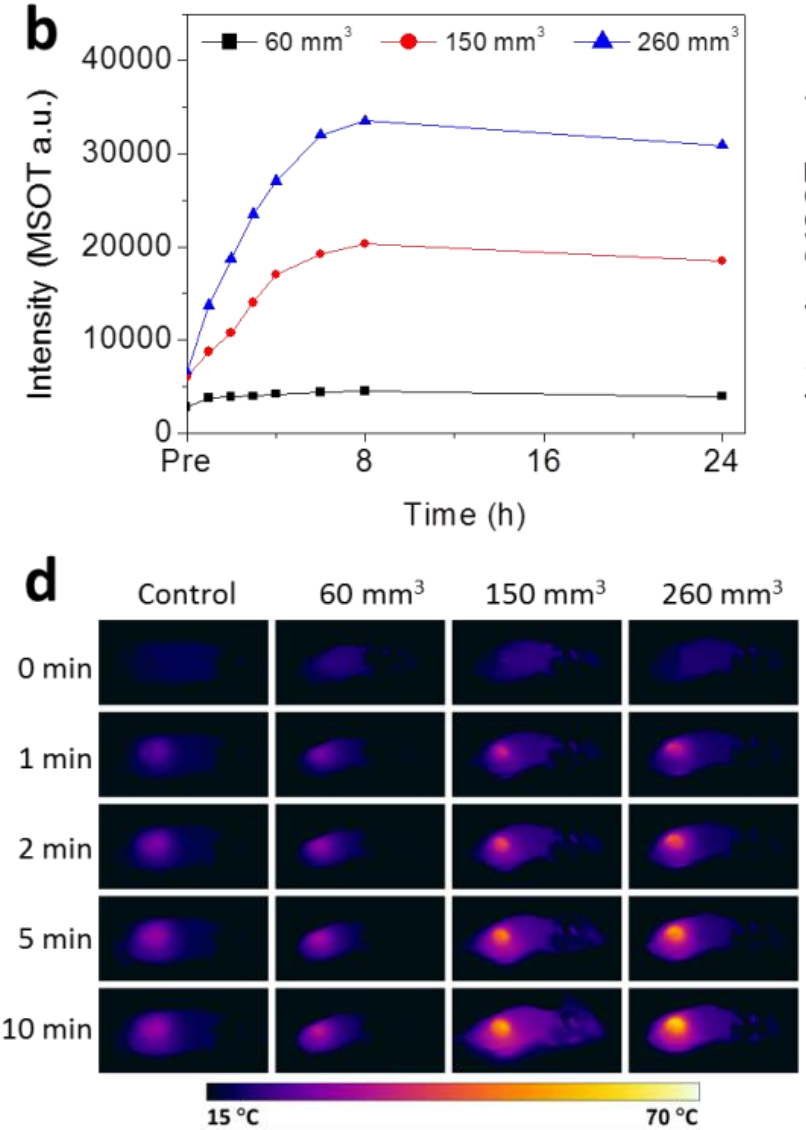

$2 \mathrm{~h}$
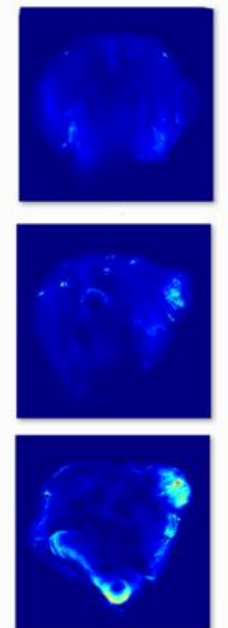

$4 \mathrm{~h}$
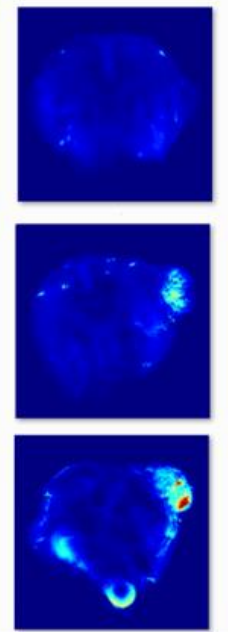

$8 \mathrm{~h}$
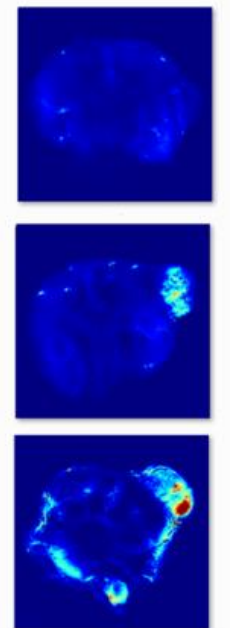

$24 \mathrm{~h}$
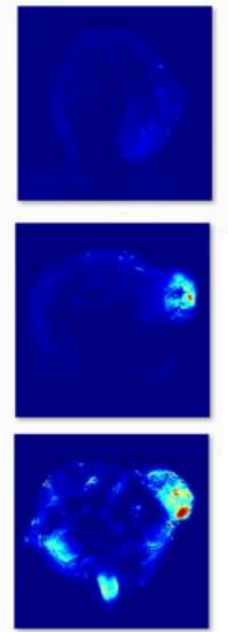
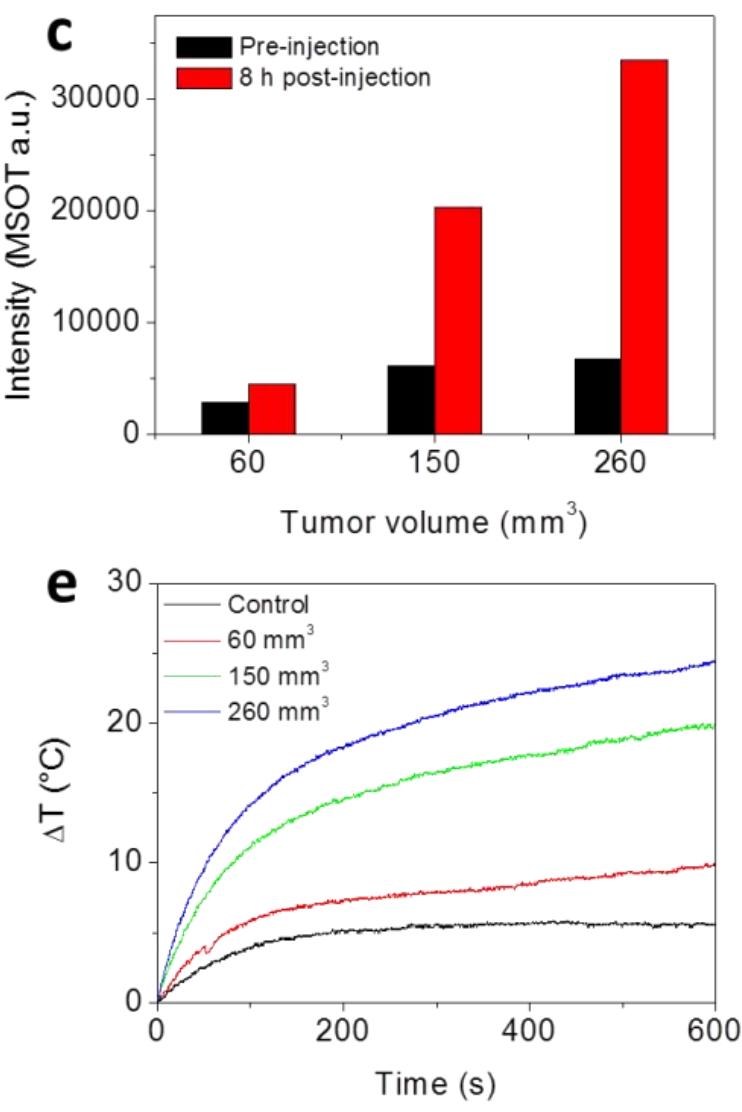

Figure 3. In-vivo photoacoustic imaging and photothermal effect of Fe(III)-gallic-acid nanoparticles. (a) Photoacoustic images of mice bearing different sized tumors before injection and at different time points post-injection with $\mathrm{Fe}(\mathrm{III})$-gallic-acid nanoparticles. (b) Photoacoustic signal variations of tumor sites in (a) as a function of post-injection time. (c) Photoacoustic signals of different sized tumors before injection and $8 \mathrm{~h}$ post-injection of $\mathrm{Fe}(\mathrm{III})$-gallic-acid nanoparticles. (d) Thermal images of mice bearing different sized tumors after injection of saline (column 1) or Fe(III)-gallic-acid nanoparticles (column 2-4) in combination with exposure to $808-\mathrm{nm}$ laser irradiation $\left(1.0 \mathrm{~W} / \mathrm{cm}^{2}, 10 \mathrm{~min}\right)$. (e) Tumor temperature changes in mice bearing different sized tumors during laser irradiation as indicated in (d). 
a
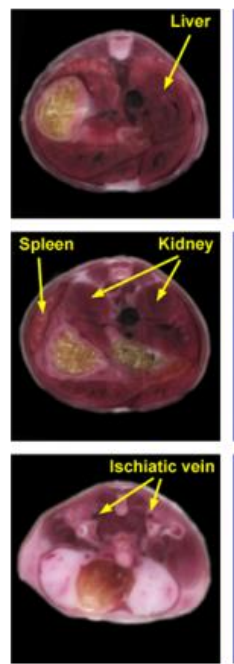

b

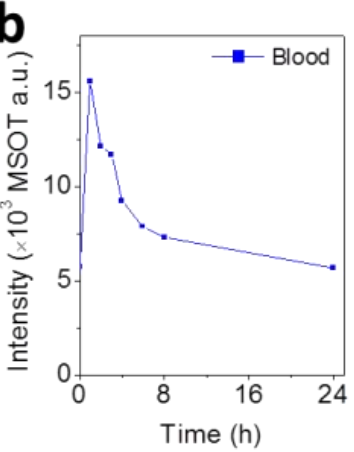

Pre
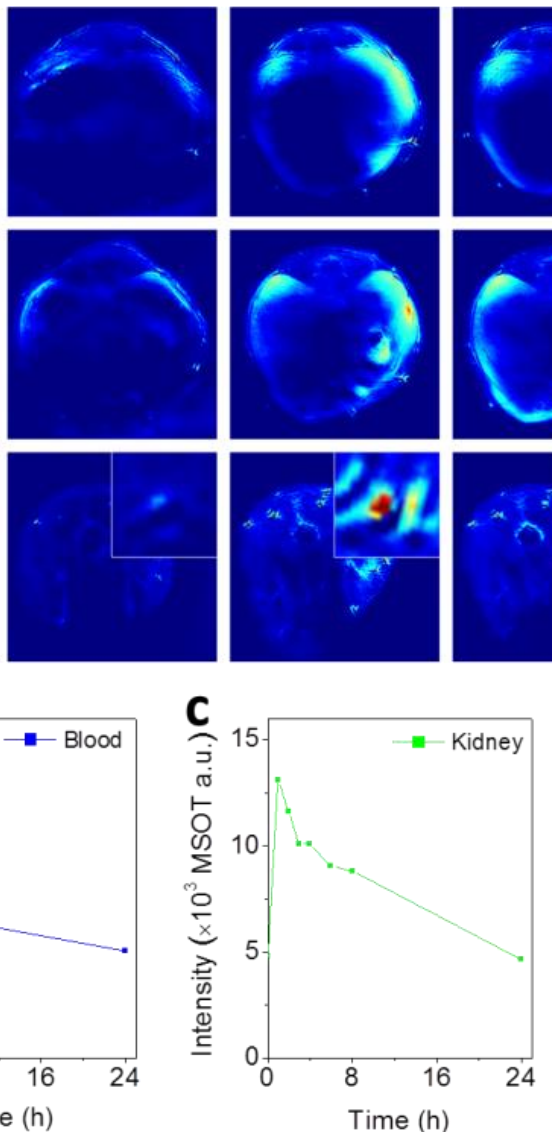

$2 \mathrm{~h}$
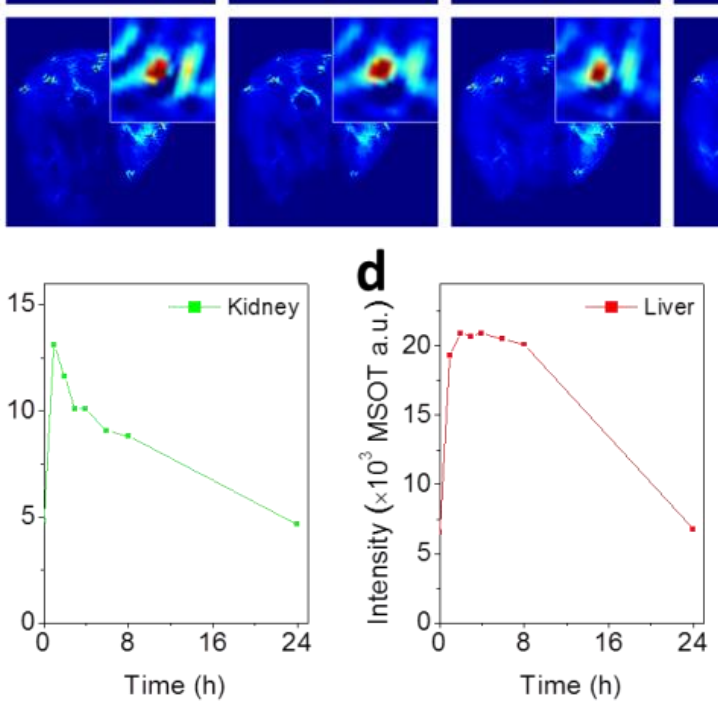

$8 \mathrm{~h}$
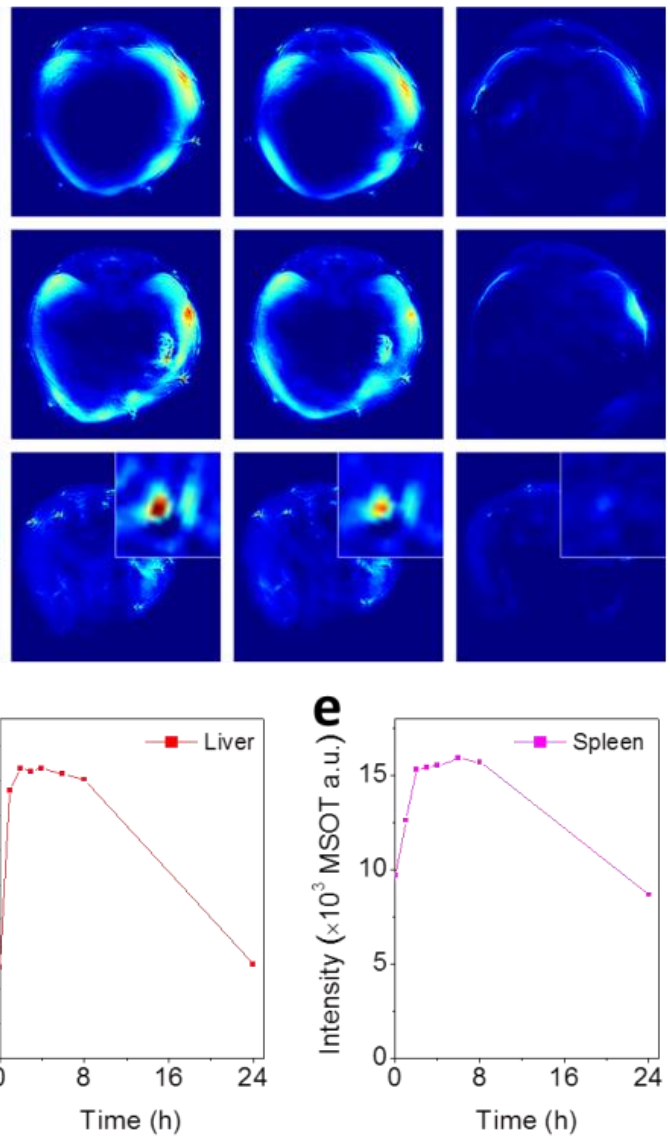

Figure 4. In-vivo biodistribution and clearance of Fe(III)-gallic-acid nanoparticles. (a) In-vivo photoacoustic images of liver, spleen, kidney, and ischiatic vein after the intravenous injection of Fe(III)-gallic-acid nanoparticles at different time intervals. (b)-(e): Photoacoustic signals of blood, kidney, liver, and spleen, respectively, as a function of time post-injection of $\mathrm{Fe}(\mathrm{III})$ gallic-acid nanoparticles. MSOT: multispectal optoacoustic tomography. 


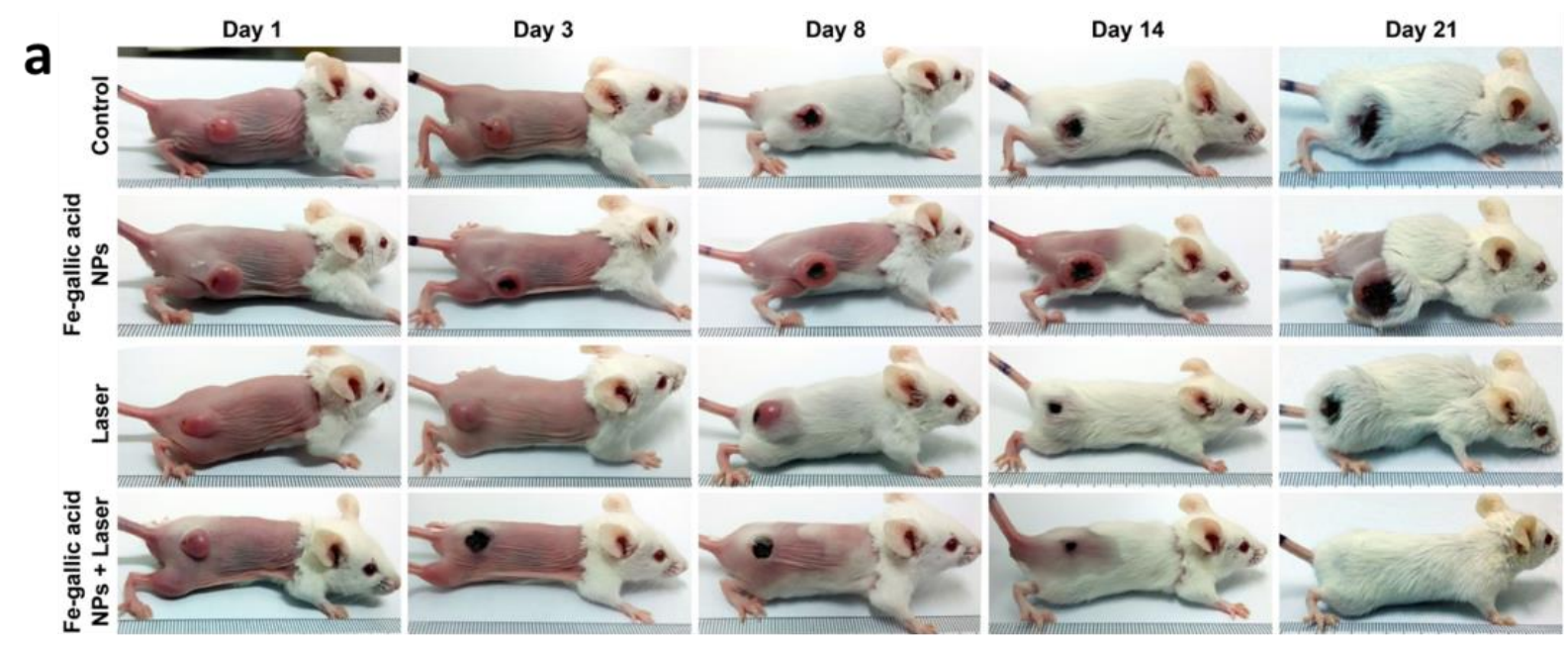

b

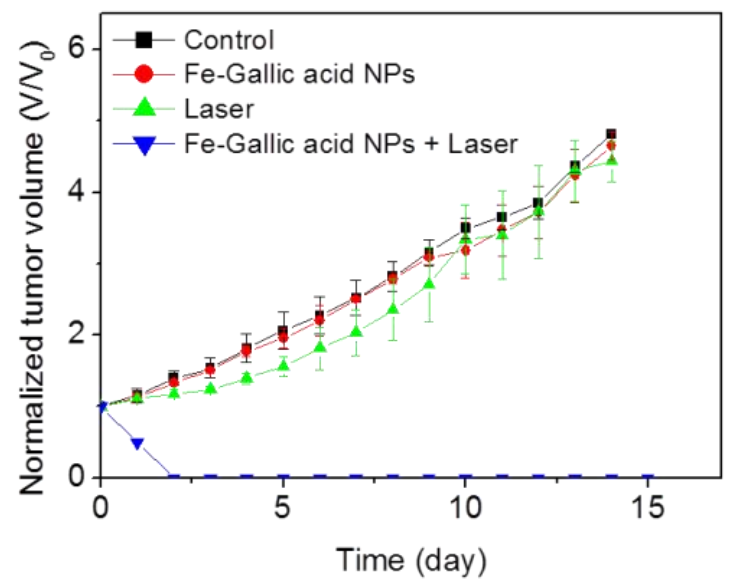

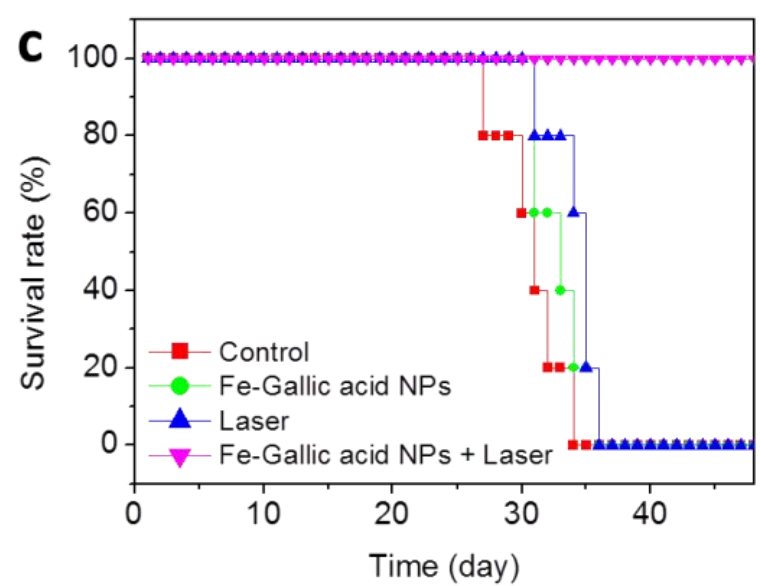

d
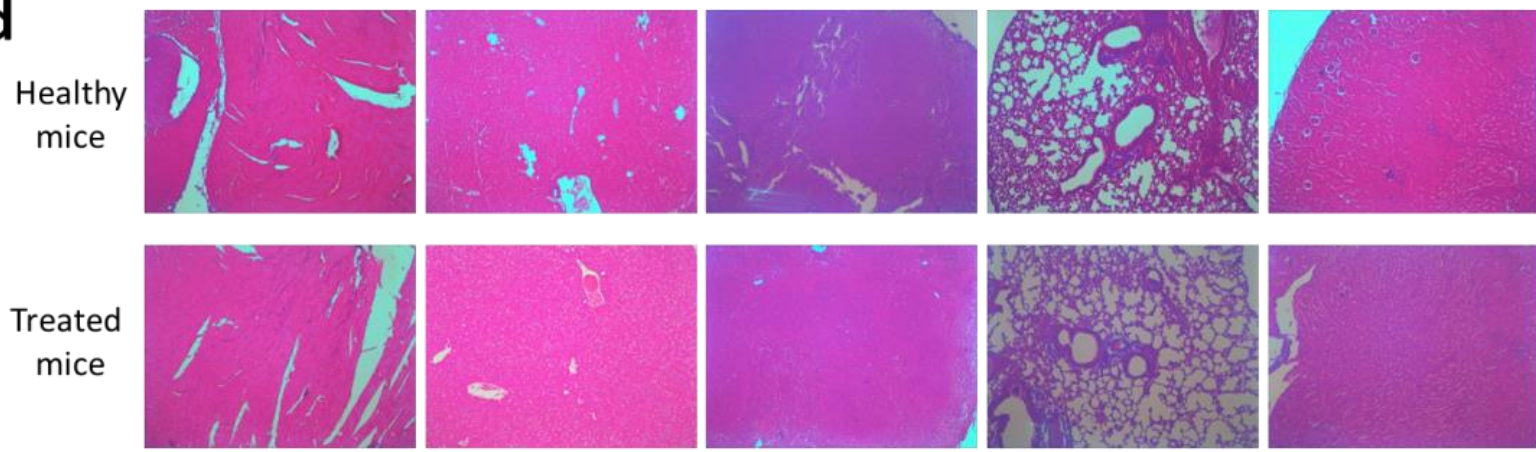

Heart

Liver

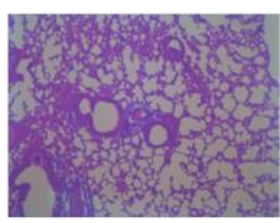

Lung

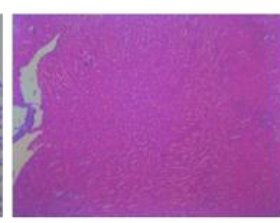

Kidney

Figure 5. In vivo photothermal therapy using $\mathrm{Fe}$ (III)-gallic-acid nanoparticles. (a) Representative photographs of mice bearing 4T1 tumors after the various different treatments indicated. (b) Corresponding growth curves of 4T1 tumors in different groups of mice after treatment. The relative tumor volumes were normalized to their initial size. (c) Survival curves of mice after various treatments as indicated. (d) H\&E stained images of major organs from untreated healthy mice and treated mice with Fe(III)-gallic-acid nanoparticle injection, taken 45 days after photothermal therapy (with tumors eliminated). 
pH-responsive biocompatible $\mathbf{F e}(\mathrm{III})$-gallic-acid nanoparticles with strong NIR absorbance are very stable in mild acidic conditions, but easily decomposed in neutral conditions, which enables the nanoparticles to be stable in a tumor and easily metabolized in other organs, thus providing a safe nanoplatform for in-vivo PAI/PTT theranostic application.

Keyword: pH-sensitive nanoparticles; metal complex nanoparticles; photoacoustic imaging; photothermal therapy

Jianfeng Zeng, Ming Cheng, Yong Wang, Ling Wen, Ling Chen, Zhen Li,* Yongyou Wu,* Mingyuan Gao,* Zhifang Chai

pH-Responsive Fe(III)-Gallic-Acid Nanoparticles for In-Vivo Photoacoustic Imaging Guided Photothermal Therapy

ToC figure
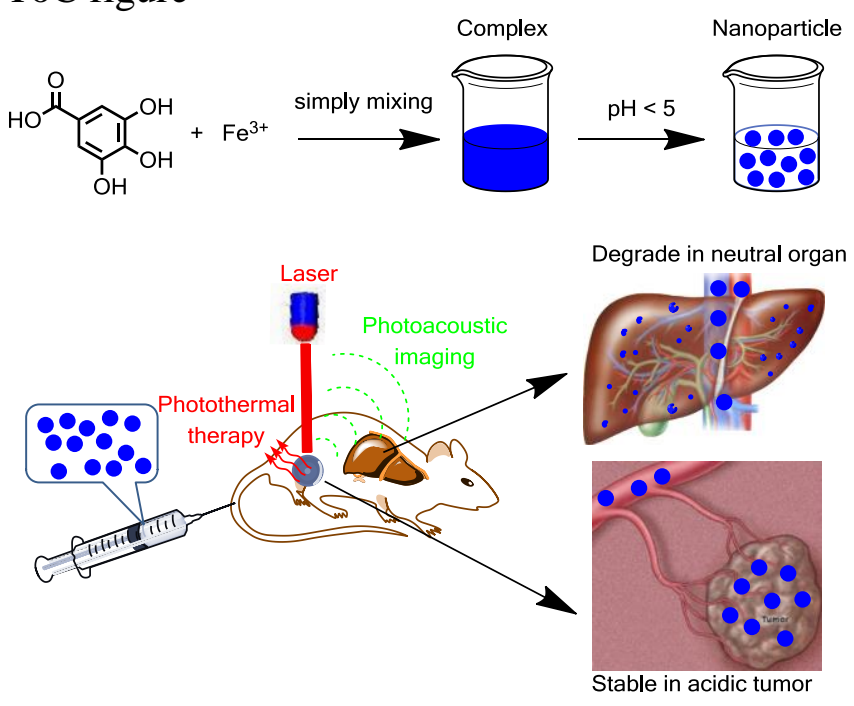
Copyright WILEY-VCH Verlag GmbH \& Co. KGaA, 69469 Weinheim, Germany, 2013.

\section{Supporting Information}

\section{pH-Responsive Fe(III)-Gallic-Acid Nanoparticles for In-Vivo Photoacoustic Imaging Guided Photothermal Therapy}

Jianfeng Zeng, Ming Cheng, Yong Wang, Ling Wen, Ling Chen, Zhen Li, * Yongyou Wu,* Mingyuan Gao,* Zhifang Chai

\section{Experimental Section}

Chemicals. Gallic acid was purchased from J\&K Chemical Ltd. Agar and intralipid were purchased from Sigma-Aldrich. Other analytical grade chemicals were purchased from Aladdin Industrial Corporation and used as received.

Synthesis of Fe(III)-gallic-acid nanoparticles. Fe(III)-gallic-acid nanoparticles were prepared by simply mixing $\mathrm{FeCl}_{3}$ and the ligand solution. In a typical synthesis, $\mathrm{FeCl}_{3}(4 \mathrm{~mL}$, $10 \mathrm{mM}$ ) and gallic acid (4 mL, $15 \mathrm{mM})$ were mixed homogenously and adjusted to $\mathrm{pH} 3.7$ by 0.1 M 4-(2-hydroxyethyl)-1-piperazineethanesulfonic acid (HEPES) buffer solution, and then incubated for $2 \mathrm{~h}$ to obtain the Fe(III)-gallic-acid nanoparticles used for further investigations.

Characterization of Fe(III)-gallic-acid nanoparticles. UV-Vis absorption spectra were recorded at room temperature on a Shimadzu UV-VIS-NIR Spectrophotometer UV3600. Transmission electron microscopy (TEM) images were collected on FEI Tecnai G2 microscopes working with an accelerating voltage of $120 \mathrm{kV}$. The hydrodynamic size was measured at $25{ }^{\circ} \mathrm{C}$ with a Malvern Zetasizer Nano ZS90 equipped with a solid-state $\mathrm{He}-\mathrm{Ne}$ $\operatorname{laser}(\lambda=633 \mathrm{~nm})$.

In-vitro Photoacoustic Effect. The photoacoustic performance of Fe(III)-gallic-acid nanoparticles was determined by a commercial multispectral optoacoustic tomography system (MSOT, iThera Medical, inVision 256). This system is equipped with an array of 256 
cylindrically focused transducers to detect photoacoustic signals, and a tunable laser system (680-980 nm, $10 \mathrm{~Hz}$ repetition rate, $8 \mathrm{~ns}$ pulse width, $120 \mathrm{~mJ}$ pulse peak energy) was used to excite the target object with optical pulses to generate the photoacoustic effect. The field of view is $25 \times 25 \mathrm{~mm}^{2}$, and the axial and lateral resolutions are 100 and $150 \mu \mathrm{m}$, respectively. For in-vitro photoacoustic imaging of $\mathrm{Fe}(\mathrm{III})$-gallic-acid nanoparticles in different concentrations, the excitation wavelength of $680 \mathrm{~nm}$ was adopted. Photoacoustic signal intensities were measured by region of interest (ROI) analysis using the MSOT imaging system software package.

In-vitro Photothermal Performance. $1 \mathrm{~mL} \mathrm{Fe(III)-gallic-acid} \mathrm{nanoparticles} \mathrm{with}$ different concentrations was placed in $5 \mathrm{~mL}$ tube and irradiated using a 808-nm laser with a power density of $0.5 \mathrm{~W} / \mathrm{cm}^{2}$. The temperature of the solution was measured with an infrared imaging device (FLIR E40 of FLIR Systems, Inc., United States) at 100 ms intervals for a total of $10 \mathrm{~min}$.

Cytotoxicity Assessments and Photothermal Ablation of Cancer Cells. Cell viability of 4T1 cells incubated with Fe(III)-gallic-acid nanoparticles followed by laser irradiation was determined by a methyl thiazolyl tetrazolium (MTT) assay. First, 4T1 cells with $5 \times 10^{4}$ cells per well were seeded into a 96-well culture plate with $200 \mu \mathrm{L}$ of RPMI1640 supplemented with $10 \%$ fetal bovine serum and $1 \%$ penicillin/streptomycin in each well, and incubated for $24 \mathrm{~h}$ at $37{ }^{\circ} \mathrm{C}$ under a humidified atmosphere with $5 \% \mathrm{CO}_{2}$. Then, the culture medium was replaced by a fresh culture medium containing $\mathrm{Fe}(\mathrm{III})$-gallic-acid nanoparticles in a series of gradient concentrations. After $24 \mathrm{~h}$ of further incubation, $20 \mu \mathrm{L}$ MTT with a concentration of $5 \mathrm{mg} / \mathrm{mL}$ was added to each well, and the plate was incubated for $4 \mathrm{~h}$ before the addition of $150 \mu \mathrm{L}$ dimethyl sulfoxide (DMSO) for dissolving the purple formazan that had been formed. Finally, the absorbance of each well was measured by using a PerkinElmer EnSpire ${ }^{\circledR}$ Multimode Plate Reader. For the laser treatment groups, after the cells 
were cultured with Fe(III)-gallic-acid nanoparticles for $24 \mathrm{~h}$, the cells were irradiated by a 808-nm laser with a power density of $0.5 \mathrm{~W} / \mathrm{cm}^{-2}$ for $10 \mathrm{~min}$. Then, the MTT assay was carried out by the same protocol mentioned above to determine the cell viability.

Animal Model. The tumor models used were established by subcutaneous injection of $50 \mu \mathrm{L} 4 \mathrm{~T} 1$ cell suspension $\left(\sim 5 \times 10^{6}\right.$ cells) into 5 week old male Balb/c mice (for the PTT study) or nude mice (for the PAI investigation) into the flank region of the right back. By monitoring the tumor growth, mice with tumor volume of $\sim 60 \mathrm{~mm}^{3}, \sim 150 \mathrm{~mm}^{3}$, and $\sim 260$ $\mathrm{mm}^{3}$, were used for in-vivo PTT and PAI studies. All animal experiments reported herein were carried out according to the protocols approved by the Soochow University Laboratory Animal Center.

In-vivo Photoacoustic Imaging. For in-vivo photoacoustic imaging studies, nude mice bearing subcutaneous tumors were anesthetized by $1.5 \%$ isoflurane delivered via a nose cone, and then Fe(III)-gallic-acid nanoparticles ( $4 \mathrm{mmol}, 200 \mu \mathrm{L}$, corresponding to $40 \mu \mathrm{mol}$ $\mathrm{Fe} / \mathrm{kg}$ body weight) were injected via the tail vein. Photoacoustic images were acquired at different time points post-injection by the MSOT system, using a wavelength of $680 \mathrm{~nm}$. For each position, 10 frames were obtained and averaged to minimize the influence of animal movement in the images.

Photothermal Therapy. 20 tumor-bearing Balb/c mice with an average tumor volume of $150 \mathrm{~mm}^{3}$ were randomly allocated into 4 groups. Mice in the treatment group were injected with $200 \mu \mathrm{L}$ of $4 \mathrm{mmol} \mathrm{Fe}(\mathrm{III})$-gallic-acid nanoparticle solution. For the control groups, the mice were treated with the same volume of saline. The laser-treated groups were irradiated with an 808-nm NIR laser (Hi-Tech Optoelectronics Co., Ltd. Beijing, China) with a power density of $1 \mathrm{~W} / \mathrm{cm}^{-2}$ for $10 \mathrm{~min}$. The tumor sizes were measured every day and calculated as the volume equal to $a \times b^{2} / 2$, where $a$ and $b$ represent the length and width of the tumor, respectively. Relative tumor volumes were obtained by dividing the initial tumor size before 
laser treatment. After 45 days, the mice from the treatment group were sacrificed, and the major organs were harvested for histological analysis.

Histological Analysis. For hematoxylin and eosin (H\&E) staining, major organs, including the liver, spleen, kidney, heart, and lung, were harvested, fixed in $10 \%$ neutral buffered formalin, processed routinely into paraffin, sectioned into thin slices, and stained withH\&E for histological analysis.

\section{Supplementary Results}

DLS analysis of Fe(III)-gallic-acid nanoparticles. Dynamic light scattering (DLS) analysis was carried out to monitor the hydrodynamic size evolution of Fe(III)-gallic-acid nanoparticles formed under different $\mathrm{pH}$. Figure S1a and S1b show the hydrodynamic size profiles of nanoparticles formed at $\mathrm{pH} 3.7$ and 4.5, respectively. The results suggest that $\mathrm{Fe}(\mathrm{III})$-gallic-acid complexes exhibit strong $\mathrm{pH}$-dependent stability, and gradually aggregate and form nanoparticles under $\mathrm{pH} 3.7$ and 4.5. 

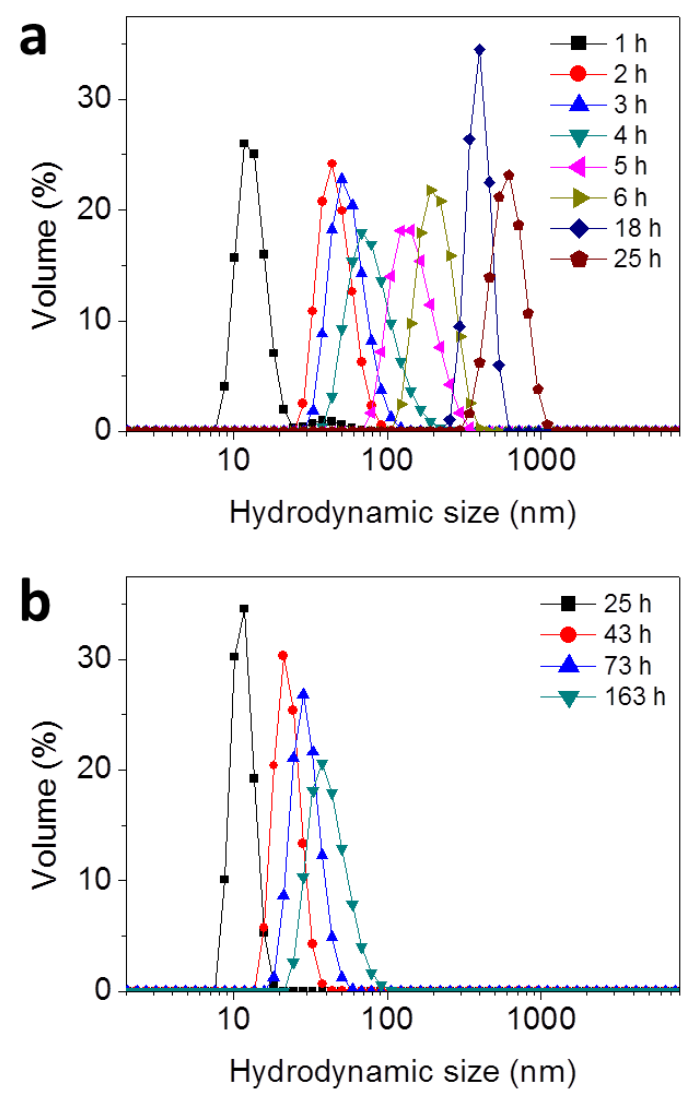

Figure S1. Hydrodynamic size profiles of Fe(III)-gallic-acid nanoparticles formed at different time points in aqueous media with $\mathrm{pH}$ values of 3.7 (a) and 4.5 (b).

Thermal imaging of Fe(III)-gallic-acid nanoparticle solution. Water and $0.5 \mathrm{mM}$ Fe(III)-gallic-acid nanoparticle solution were irradiated using a 808-nm laser with a power density of $0.5 \mathrm{~W} / \mathrm{cm}^{2}$. Figure $\mathrm{S} 2$ presents thermal images collected by an infrared imaging device, which demonstrate that $\mathrm{Fe}(\mathrm{III})$-gallic-acid nanoparticles are a rather effective photothermal agent.

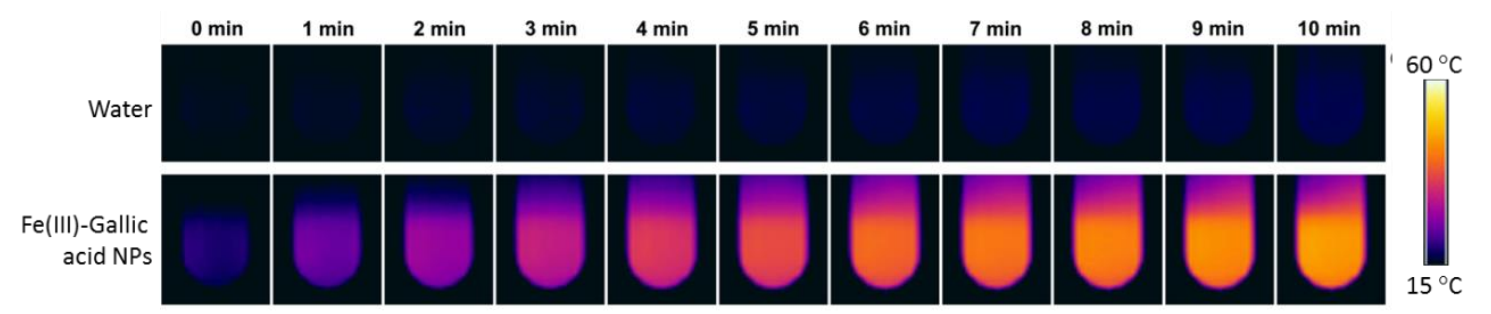

Figure S2. Thermal images of water and $0.5 \mathrm{mM} \mathrm{Fe(III)-gallic-acid} \mathrm{nanoparticles} \mathrm{under} \mathrm{808-}$ $\mathrm{nm}$ laser irradiation at a power density of $0.5 \mathrm{~W} / \mathrm{cm}^{2}$ for $10 \mathrm{~min}$. 
Calculation of the photothermal conversion efficiency. Under the room temperature of $25{ }^{\circ} \mathrm{C}, 0.5 \mathrm{mM} \mathrm{Fe}(\mathrm{III})$-gallic-acid nanoparticles solution was loaded into a cuvette and irradiated using a 808-nm laser, followed by natural cooling after laser light was turned off. The temperature profile monitored is shown in Figure S3a. The photothermal conversion efficiency is calculated according to the following equation. ${ }^{[1]}$ The photothermal conversion efficiency $\eta$ can be given as

$$
\eta=\frac{m \cdot c \cdot\left(T_{\max }-T_{\max , \text { water }}\right)}{I \cdot\left(1-10^{-A}\right) \cdot \tau_{s}}
$$

where $m$ is the solution mass and equal to $1.0 \mathrm{~g}$ in the current study, $c$ is the heat capacity of water and equal to $4.2 \mathrm{~J} / \mathrm{g}, T_{\max }$ and $T_{\max \text {,water }}$ are the maximum temperature change for nanopaticles solution and water, which are $21.2{ }^{\circ} \mathrm{C}$ and $1.4^{\circ} \mathrm{C}$, respectively, $I$ is the laser power and equal to $0.5 \mathrm{~W}$ in the current study, $A$ is the absorbance of nanoparticles solution at $808 \mathrm{~nm}$ and equal to $0.4294, \tau_{\mathrm{s}}$ is the system time constant and equal to $396.4 \mathrm{~s}$ according to the linear regression of the cooling profile (Figure S3b). The photothermal conversion efficiency is calculated to be $66.8 \%$ by using these parameters.
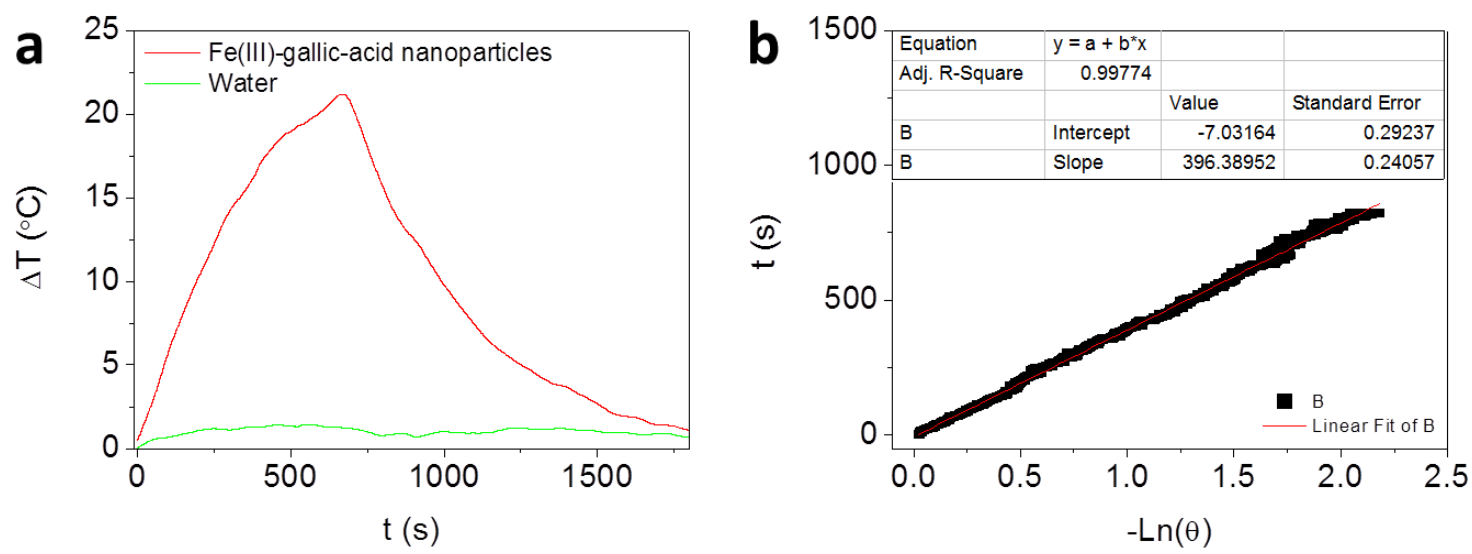

Figure S3. (a) The temperature profile of a $0.5 \mathrm{mM} \mathrm{Fe(III)-gallic-acid} \mathrm{nanoparticles} \mathrm{solution}$ irradiated with a 808-nm laser, followed by natural cooling after laser was turned off. (b) Determination of the system time constant using linear regression of the cooling profile shown in (a). 
DLS analyses of Fe(III)-gallic-acid nanoaprticles in $10 \%$ FBS. Figure S4 shows the hydrodynamic size evolution of $\mathrm{Fe}(\mathrm{III})$-gallic-acid nanoparticles incubated in $\mathrm{pH} 7.0$ aqueous medium and $10 \%$ FBS with different $\mathrm{pH}$ values. Fe(III)-gallic-acid nanoparticles show a slower degradation in $10 \% \mathrm{FBS}(\mathrm{pH}=7)$ than in neutral water. If $\mathrm{Fe}(\mathrm{III})$-gallic-acid nanoparticles were incubated in weak acidic 10\% FBS (pH 5.0 and 5.6), they remained stable in $6 \mathrm{~h}$ but precipitated after $24 \mathrm{~h}$.

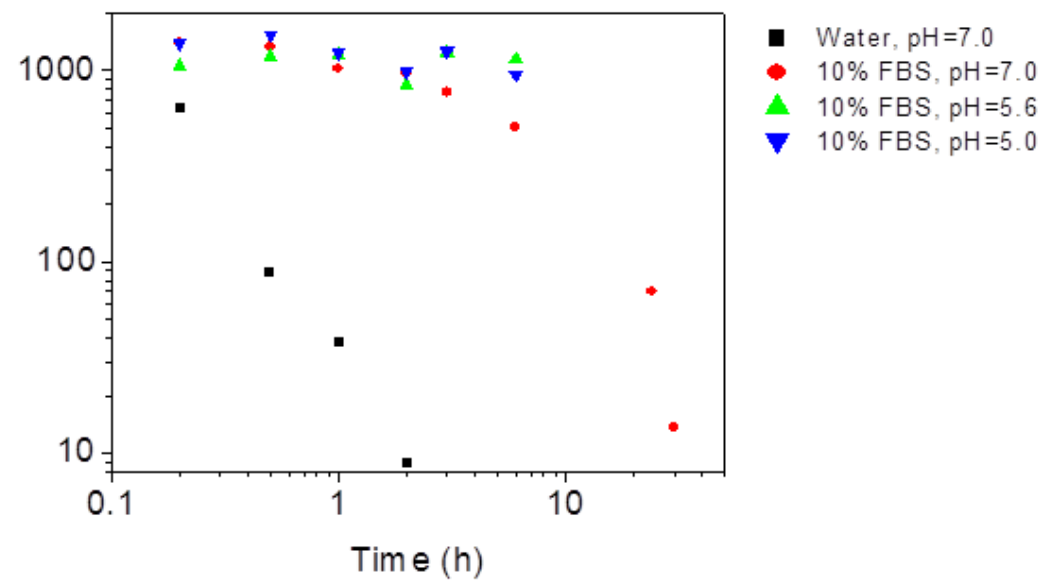

Figure S4. Evolution of hydrodynamic size of Fe(III)-gallic-acid nanoparticles incubated in $\mathrm{pH} 7.0$ aqueous media and 10\% FBS with different $\mathrm{pH}$ values.

Reference

[1] X. Ding, C. H. Liow, M. Zhang, R. Huang, C. Li, H. Shen, M. Liu, Y. Zou, N. Gao, Z.

Zhang, Y. Li, Q. Wang, S. Li, J. Jiang, Journal of the American Chemical Society 2014, 136, 15684. 